\title{
Myeloperoxidase-Dependent LDL Modifications in Bloodstream Are Mainly Predicted by Angiotensin II, Adiponectin, and Myeloperoxidase Activity: A Cross-Sectional Study in Men
}

\author{
Karim Zouaoui Boudjeltia, ${ }^{1}$ Cédric Delporte, ${ }^{2}$ Pierre Van Antwerpen, ${ }^{2}$ \\ Thierry Franck, ${ }^{3}$ Didier Serteyn, ${ }^{3}$ Nicole Moguilevsky, ${ }^{4}$ \\ Martine Raes, ${ }^{5}$ Luc Vanhamme, ${ }^{6}$ Michel Vanhaeverbeek, \\ Alain Van Meerhaeghe, ${ }^{1}$ and Thierry Roumeguère ${ }^{1,7}$ \\ ${ }^{1}$ Laboratory of Experimental Medicine (ULB 222 Unit), CHU de Charleroi, A. Vésale Hospital, Université Libre de Bruxelles, \\ Rue de Gozée 706, 6110 Montigny-le-Tilleul, Belgium \\ ${ }^{2}$ Laboratory of Pharmaceutical Chemistry and Analytical Platform, Faculty of Pharmacy, Université Libre de Bruxelles, \\ Boulevard du Triomphe, Campus Plaine CP 205/5, 1050 Brussels, Belgium \\ ${ }^{3}$ Center for Oxygen Research and Development, Institute of Chemistry B6a, University of Liège, 4000 Liège, Belgium \\ ${ }^{4}$ Technology Transfer Office, University of Namur, rue de Bruxelles 61, 5000 Namur, Belgium \\ ${ }^{5}$ Laboratory of Biochemistry and Cellular Biology (NARILIS), University of Namur, rue de Bruxelles, 61, 5000 Namur, Belgium \\ ${ }^{6}$ Institute for Molecular Biology and Medicine (IBMM), Université Libre de Bruxelles, Rue des Professeurs Jeener et Brachet 12, \\ 6041 Gosselies, Belgium \\ ${ }^{7}$ Department of Urology, Erasme University Hospital, Université Libre de Bruxelles, Route de Lennik 808, 1070 Brussels, Belgium
}

\begin{abstract}
Correspondence should be addressed to Karim Zouaoui Boudjeltia; karim.zouaoui@chu-charleroi.be and Cédric Delporte; cedric.delporte@ulb.ac.be
\end{abstract}

Received 1 August 2013; Revised 7 October 2013; Accepted 7 October 2013

Academic Editor: Ronit Shiri-Sverdlov

Copyright (C) 2013 Karim Zouaoui Boudjeltia et al. This is an open access article distributed under the Creative Commons Attribution License, which permits unrestricted use, distribution, and reproduction in any medium, provided the original work is properly cited.

\begin{abstract}
The present paradigm of atherogenesis proposes that low density lipoproteins (LDLs) are trapped in subendothelial space of the vascular wall where they are oxidized. Previously, we showed that oxidation is not restricted to the subendothelial location. Myeloperoxidase (MPO), an enzyme secreted by neutrophils and macrophages, can modify LDL (Mox-LDL) at the surface of endothelial cells. In addition we observed that the activation of the endothelial cells by angiotensin II amplifies this process. We suggested that induction of the NADPH oxidase complex was a major step in the oxidative process. Based on these data, we asked whether there was an independent association, in 121 patients, between NADPH oxidase modulators, such as angiotensin II, adiponectin, and levels of circulating Mox-LDL. Our observations suggest that the combination of blood angiotensin II, MPO activity, and adiponectin explains, at least partially, serum Mox-LDL levels.
\end{abstract}

\section{Introduction}

Atherosclerosis is an inflammatory disease involving a crosstalk between vascular cells, monocytes, proinflammatory cytokines, chemokines, and growth factors [1-3]. The current paradigm of early atherosclerosis claims that lowdensity lipoprotein (LDL) particles are trapped in the subendothelial space of the vascular wall where they can be oxidized. The precise physiological process for LDL oxidation in vivo is still largely unknown and the occurrence of LDL 
oxidation outside the lesion sites has not definitively been ruled out yet.

Evidence accumulated during the last decade has suggested implication of myeloperoxidase (MPO) in inflammation leading to atherogenesis. MPO is produced by macrophages and neutrophils [4] and via its chlorination activity, MPO produces hypochlorous acid $(\mathrm{HOCl})$ from hydrogen peroxide $\left(\mathrm{H}_{2} \mathrm{O}_{2}\right)$ and chloride anion $\left(\mathrm{Cl}^{-}\right)$. $\mathrm{HOCl}$ can oxidize protein-bound amino acid residues among which the formation of 3-chlorotyrosine is considered as specific of the activity of MPO as the latter is the only human enzyme able to produce $\mathrm{HOCl}$. In the context of atherogenesis, MPO, 3-chlorotyrosine, and MPO-dependent modified LDL (MoxLDL) have all been detected in human atherosclerotic lesions and in the bloodstream [5-8].

We previously demonstrated that Mox-LDL generation could occur in vitro at the surface of the endothelial cells suggesting that it was not restricted to the subendothelial space in vivo [9]. The triad made up by endothelial cell, circulating LDL and MPO, allowed a synergic mechanism for producing Mox-LDL. The starting point of this reaction is the generation of superoxide anion $\left(\mathrm{O}_{2}^{-}\right)$by the membrane bound nicotinamide-adenine-dinucleotide phosphate (NADPH) oxidase. $\mathrm{O}_{2}{ }^{-}$is further dismutated into $\mathrm{H}_{2} \mathrm{O}_{2}$ a substrate for MPO to produce $\mathrm{HOCl}$. We recently reported, in two different clinical situations, that this indeed enables MPO to rapidly modify LDL and serum proteins by oxidations $[8,10]$. Furthermore, NADPH oxidase is activated and upregulated by angiotensin II (ANGII) via the ANGII type I (AT1) receptor present at the surface of endothelial cells [11]. This enzymatic complex therefore plays a central role in the Mox-LDL generation [9].

Based on these data, we wondered whether there was an independent association between NADPH oxidase modulators, such as ANGII, adiponectin [12], and levels of circulating Mox-LDL. To test this hypothesis, we report the data observed in a cohort of male patients $(n=121)$ consulting for lower urinary tract symptoms (LUTS). Indeed, LUTS is associated with the erectile dysfunction, which is an early predictive sign for atherosclerotic cardiovascular events [13].

\section{Material and Methods}

2.1. Patients. Subjects were 121 males with a mean age of $58.8 \pm$ 10.8 who consulted for lower urinary tract symptoms (LUTS) at the Erasme University Hospital. This study conforms with the Declaration of Helsinki and its protocol was approved by the Ethics Committee of the Erasme University Hospital. Finally, all subjects gave their written informed consent.

2.2. Standard Analyses. Blood samples were centrifuged for 10 minutes at $4000 \mathrm{~g}$ and the supernatant was collected and frozen. Blood tests were performed at the Laboratory of Experimental Medicine of the University Hospital of Charleroi, Site A. Vésale, Unit 222, ULB. The following parameters were measured: C-reactive protein (CRP), blood glucose, total cholesterol, triglycerides, HDL-cholesterol (standard laboratory techniques PLC), and adiponectin. LDL-cholesterol levels were calculated using the Friedewald formula (LDL-chol $(\mathrm{mg} / \mathrm{dL})=$ T-chol-HDL-chol-TG/5).

2.3. MPO and Mox-LDL Analyses. Mox-LDL was measured using a sandwich ELISA kit [9]. The specificity of the antibody was further assessed by analyzing LDL oxidized with peroxynitrite $(0,10,100$, and $1000 \mu \mathrm{M})$ and comparing with LDL oxidized by MPO/hydrogen peroxide/chloride. Other oxidants produced by $\mathrm{MPO}$ such as $\mathrm{HOSCN} /{ }^{-} \mathrm{OSCN}$, $\mathrm{HOBr} /{ }^{-} \mathrm{OBr}$, and $\mathrm{HOI} /{ }^{-} \mathrm{OI}$ (from $\mathrm{MPO} /$ hydrogen peroxide/corresponding halide) were also used to oxidize LDL and to test the specificity of LDL. It resulted in the fact that the antibody is highly specific for Mox-LDL.

The active and total MPO contents in plasma were measured using the licensed SIEFED and ELISA (ELIZEN MPO, Zentech SA, Belgium) methods [14]. By using these two techniques, we are able to distinguish active and total MPO contents in plasma and to determine the specific activity of MPO (MPO activity/MPO antigen ratio).

2.4. Angiotensin II, Adiponectin, and Interleukin-8 Analyses. ANGII was determined in plasma by a radioimmunoassay kit (BioSource, Nivelles, Belgium). IL-8 and adiponectin concentrations were quantified using ELISA tests (Becton Dickinson).

2.5. Statistic. Data were analyzed using the SigmaPlot 12.0 software (Systat, San Jose, CA). Results were considered statistically significant with a two-tailed $P<0.05$. Two models of multiple linear regression analysis were tested using a backward stepwise selection of explicative variables.

\section{Results and Discussion}

The purpose of the present study was to explore whether there is an independent association between ANGII (an NADPH modulator), adiponectin, and levels of circulating Mox-LDL. In this context we analyzed various parameters within 121 male subjects who consulted for the first time for LUTS. Table 1 shows the means and SD of the parameters measured or calculated within patients.

Table 2 describes two models of multivariate analysis of backward regression in these subjects. The standardized regression coefficients are given for each model. As shown in Table 2, in the first model (Model 1) we set Mox-LDL as the dependent variable, while the independent variables included the parameters described above. Significant linear correlations were found between Mox-LDL levels and ANGII, and MPO activity (both positively) and also adiponectin content (negatively). In the second model (Model 2) the Mox$\mathrm{LDL} / \mathrm{ApoB}$ ratio (an estimation of the proportion of MPOmodified LDL in the bloodstream) was set as dependent variable and the same set of above parameters as independent variables. The same variables as in Model 1 were found to predict the Mox-LDL/ApoB ratio.

Our observations suggest that the combination of blood ANGII, MPO, activity and adiponectin explains at least 
TABle 1: Patient parameters.

\begin{tabular}{lcc}
\hline$N=121$ & Mean & $\mathrm{SD}$ \\
\hline Age $($ years $)$ & 59 & 11 \\
BMI $\left(\mathrm{kg} / \mathrm{m}^{2}\right)$ & 26 & 4 \\
Glycemia $(\mathrm{mg} / \mathrm{dL})$ & 107 & 48 \\
Total cholesterol $(\mathrm{mg} / \mathrm{dL})$ & 209 & 39 \\
Triglycerides $(\mathrm{mg} / \mathrm{dL})$ & 184 & 142 \\
HDL cholesterol $(\mathrm{mg} / \mathrm{dL})$ & 53 & 18 \\
LDL cholesterol $(\mathrm{mg} / \mathrm{dL})$ & 122 & 35 \\
Interleukin-8 $(\mathrm{ng} / \mathrm{mL})$ & 17 & 10 \\
Mox-LDL $(\mu \mathrm{g} / \mathrm{mL})$ & 9 & 13 \\
Mox-LDL/ApoB $(\mu \mathrm{g} / \mathrm{mg})$ & 0.1 & 0.2 \\
Angiotensin II $(\mathrm{pmol} / \mathrm{L})$ & 14 & 11 \\
Adiponectin $(\mathrm{ng} / \mathrm{mL})$ & 5252 & 4197 \\
MPO activity $(\mathrm{MPOA})(\mathrm{mU} / \mathrm{mL})$ & 27 & 18 \\
MPO antigen $(\mathrm{MPOAg})(\mathrm{ng} / \mathrm{mL})$ & 50 & 36 \\
MPOA/MPOAg $(\mathrm{mU} / \mathrm{ng})$ & 0.6 & 0.2 \\
\hline
\end{tabular}

Conversion for lipids: total cholesterol, HDL-c and LDL-c: $1 \mathrm{mmol} / \mathrm{L}=$ $38.67 \mathrm{mg} / \mathrm{dL}$.

Triglycerides: $1 \mathrm{mmol} / \mathrm{L}=38.67 \mathrm{mg} / \mathrm{dL}$

BMI: body mass index.

TABLE 2: Multivariate analysis of backward regressions in the total population.

\begin{tabular}{lcc}
\hline$N=121$ & $\begin{array}{c}\text { Standardized } \\
\text { regression } \\
\text { coefficient }\end{array}$ & $P$ value \\
\hline $\begin{array}{l}\text { Model } 1 R=0.52, F=9.7, \\
P<0.001\end{array}$ & 0.425 & $<0.001$ \\
ANGII & 0.236 & 0.018 \\
MPO activity & -0.196 & 0.05 \\
Adiponectin & & \\
Model 2 $R=0.58, F=12.6$, & & \\
$P<0.001$ & 0.446 & $<0.001$ \\
ANGII & 0.315 & 0.001 \\
MPO activity & -0.201 & 0.03 \\
Adiponectin & & \\
\hline
\end{tabular}

Parameters introduced in the stepwise multiple regression analysis: age, BMI, adiponectin, IL-8, total cholesterol, HDL-c, LDL-c, triglycerides, glycaemia, MPO antigen, MPO activity, and the ratio MPO activity/MPO antigen. Model 1: the Mox-LDL is the dependent variable. Model 2: the Mox$\mathrm{LDL} / \mathrm{ApoB}$ is the dependent variable.

partially the serum Mox-LDL levels. They corroborate and extend our previous data showing that oxidation could also take place at the surface of endothelial cells $[9,15]$ and that plasma level of Mox-LDL follows the level of MPO in patients during a hemodialysis process $[15,16]$. They are underpinned by established physiopathological mechanisms as endothelial cells express NADPH oxidase, the activity and expression of which are increased by ANGII binding to the AT1 receptor [12]. In support of our proposal, we previously observed that hypertensive COPD patients treated by angiotensin-converting enzyme inhibitors had reduced levels of circulating Mox-LDL (our unpublished data). This is an alternative and complementary explanation to the common model positing that the presence of modified LDL in the circulation is due to the back diffusion of modified LDL from the vessel to the circulation and is a marker of plaque instability in patients with coronary artery disease. Furthermore, it recently arose that human peroxidasin 1 , also called vascular peroxidase 1 (VPO1), might be involved in the in vivo production of $\mathrm{HOCl}$ and so potentially contributes to the oxidation of LDL [17]. Moreover, VPO1 was also suggested as an inductor of vascular smooth muscle cell proliferation [18]. However, further experiments are needed as the formation of $\mathrm{HOCl}$ by $\mathrm{VPOl}$ is low at physiological $\mathrm{pH}$.

We also uncovered a negative linear correlation between oxidative stress and adiponectin in our multiple linear regression models (Table 2). This is in agreement with the observation that adiponectin reduced in vitro and in vivo the NADPH oxidase activity and hence oxidative stress [12]. It is also in support of the general agreement that adiponectin, which is secreted by fat tissue, is antiatherogenic by modulating cytokine inflammatory cascades and inhibiting cholesterol incorporation.

In sum, our study suggests that the combined action of ANGII, MPO, and adiponectin might explain the serum Mox-LDL levels. A definitive validation or invalidation of the proposed role of ANGII in the generation of serum Mox-LDL will request a double blind randomized crossover study comparing subjects receiving an angiotensin-converting enzyme inhibitor or an angiotensin II receptor antagonist and a placebo.

\section{Abbreviations}

ANGII: Angiotensin II

ApoB-100: Apolipoprotein B-100

LDL: $\quad$ Low-density lipoprotein

LUTS: Lower urinary tract symptoms

MPO: Myeloperoxidase

Mox-LDL: Low-density lipoprotein modified by the MPO- $\mathrm{H}_{2} \mathrm{O}_{2}$-chloride system

NADPH: Nicotinamide-adenine-dinucleotide phosphate.

\section{Conflict of Interests}

The authors declare that they have no conflict of interests.

\section{Authors' Contribution}

Karim Zouaoui Boudjeltia and Cédric Delporte equally contributed to this paper.

\section{References}

[1] L. Lind, "Circulating markers of inflammation and atherosclerosis," Atherosclerosis, vol. 169, no. 2, pp. 203-214, 2003.

[2] H. Noels and C. Weber, "catching up with important players in atherosclerosis: type i interferons and neutrophils," Current Opinion in Lipidology, vol. 22, no. 2, pp. 144-145, 2011. 
[3] C. Weber and H. Noels, "Atherosclerosis: current pathogenesis and therapeutic options," Nature Medicine, vol. 17, no. 11, pp. 1410-1422, 2011.

[4] S. J. Klebanoff, "Myeloperoxidase: friend and foe," Journal of Leukocyte Biology, vol. 77, no. 5, pp. 598-625, 2005.

[5] A. Daugherty, J. L. Dunn, D. L. Rateri, and J. W. Heinecke, "Myeloperoxidase, a catalyst for lipoprotein oxidation, is expressed in human atherosclerotic lesions," Journal of Clinical Investigation, vol. 94, no. 1, pp. 437-444, 1994.

[6] E. Malle, G. Marsche, J. Arnhold, and M. J. Davies, "Modification of low-density lipoprotein by myeloperoxidase-derived oxidants and reagent hypochlorous acid," Biochimica et Biophysica Acta, vol. 1761, no. 4, pp. 392-415, 2006.

[7] M. J. Davies, C. L. Hawkins, D. I. Pattison, and M. D. Rees, "Mammalian heme peroxidases: from molecular mechanisms to health implications," Antioxidants and Redox Signaling, vol. 10, no. 7, pp. 1199-1234, 2008.

[8] C. Delporte, T. Franck, C. Noyon et al., "Simultaneous measurement of protein-bound 3-chlorotyrosine and homocitrulline by LC-MS/MS after hydrolysis assisted by microwave: application to the study of myeloperoxidase activity during hemodialysis," Talanta, vol. 99, pp. 603-609, 2012.

[9] K. Zouaoui Boudjeltia, N. Moguilevsky, I. Legssyer et al., "Oxidation of low density lipoproteins by myeloperoxidase at the surface of endothelial cells: an additional mechanism to subendothelium oxidation," Biochemical and Biophysical Research Communications, vol. 325, no. 2, pp. 434-438, 2004.

[10] K. Boudjeltia, B. Faraut, M. J. Esposito et al., "Temporal dissociation between myeloperoxidase (MPO)-modified LDL and $\mathrm{MPO}$ elevations during chronic sleep restriction and recovery in healthy young men," PLoS ONE, vol. 6, no. 11, Article ID e28230, 2011.

[11] S. Higuchi, H. Ohtsu, H. Suzuki, H. Shirai, G. D. Frank, and S. Eguchi, "Angiotensin II signal transduction through the AT1 receptor: novel insights into mechanisms and pathophysiology," Clinical Science, vol. 112, no. 7-8, pp. 417-428, 2007.

[12] C. Roberto, P. Pasquale, D. S. Serena et al., "Atorvastatin inhibits oxidative stress via adiponectin-mediated NADPH oxidase down-regulation in hypercholesterolemic patients," Atherosclerosis, vol. 213, no. 1, pp. 225-234, 2010.

[13] T. Roumeguére, K. Z. Boudjeltia, C. Hauzeur, C. Schulman, M. Vanhaeverbeek, and E. Wespes, "Is there a rationale for the chronic use of phosphodiesterase-5 inhibitors for lower urinary tract symptoms secondary to benign prostatic hyperplasia?" BJU International, vol. 104, no. 4, pp. 511-517, 2009.

[14] T. Franck, S. Kohnen, K. Z. Boudjeltia et al., "A new easy method for specific measurement of active myeloperoxidase in human biological fluids and tissue extracts," Talanta, vol. 80, no. 2, pp. 723-729, 2009.

[15] C. Delporte, P. van Antwerpen, L. Vanhamme, T. Roumeguere, and K. Zouaoui Boudjeltia, "Low-density lipoprotein modified by myeloperoxidase in inflammatory pathways and clinical studies," Mediators Inflammation, vol. 2013, Article ID 971579, 18 pages, 2013.

[16] M. Vaes, K. Z. Boudjeltia, P. van Antwerpen et al., "Lowdensity lipoprotein oxidation by myeloperoxidase occurs in the blood circulation during hemodialysis," Atherosclerosis, vol. 7, Proceedings of the 4 th international symposium on Th-P15:146, no. 3, p. 525, 2006.

[17] H. Li, Z. Cao, D. R. Moore et al., "Microbicidal activity of vascular peroxidase 1 in human plasma via generation of hypochlorous acid," Infection and Immunity, vol. 80, no. 7, pp. 2528-2537, 2012.

[18] R. Shi, C. Hu, Q. Yuan et al., "Involvement of vascular peroxidase 1 in angiotensin II-induced vascular smooth muscle cell proliferation," Cardiovascular Research, vol. 91, no. 1, pp. 27-36, 2011. 


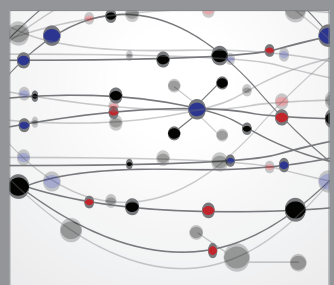

The Scientific World Journal
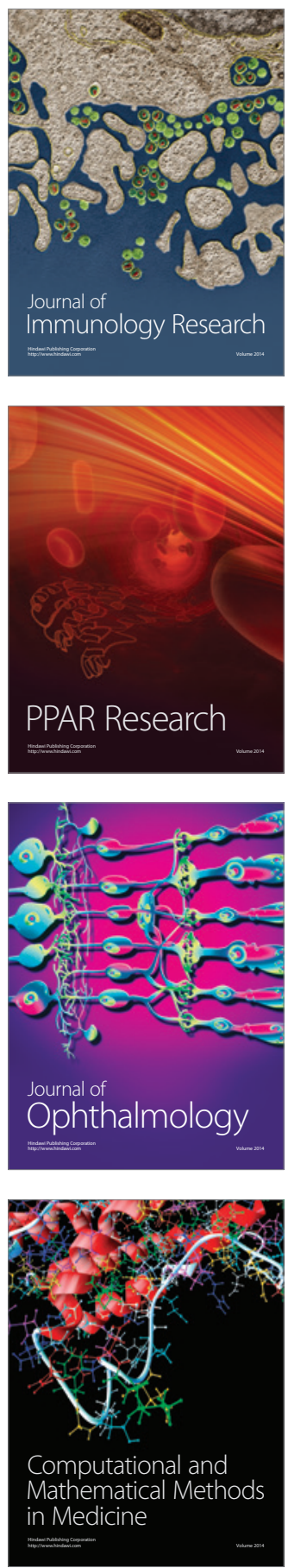

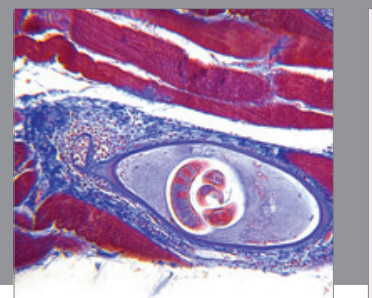

Gastroenterology

Research and Practice
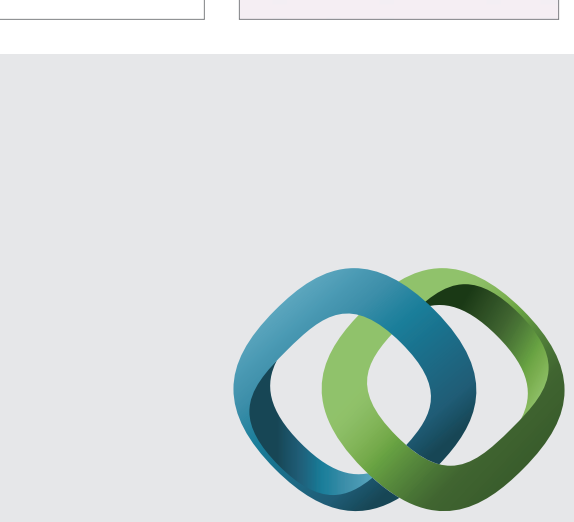

\section{Hindawi}

Submit your manuscripts at

http://www.hindawi.com
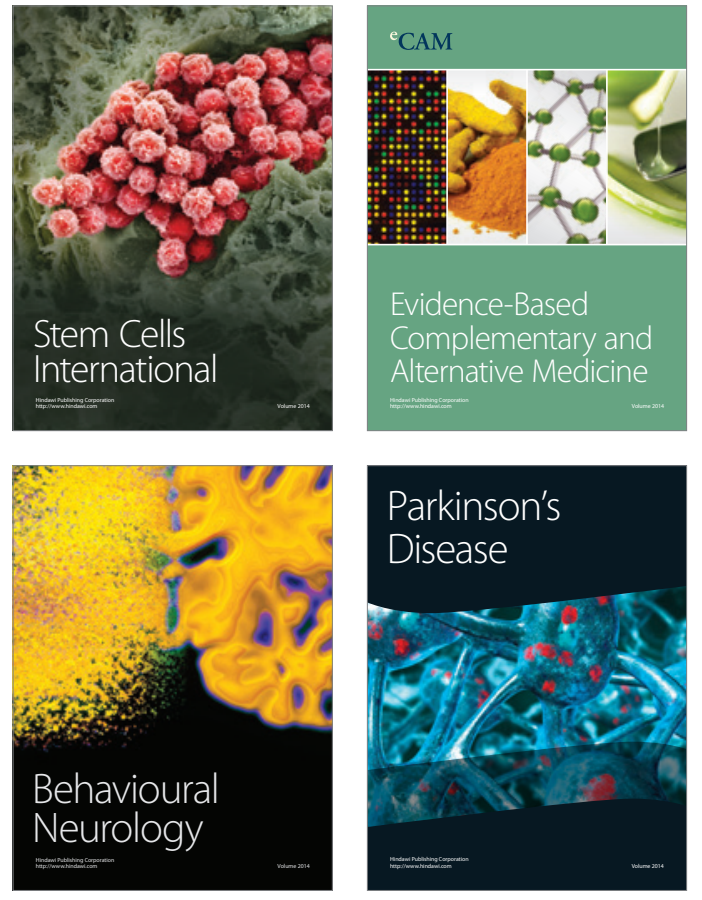
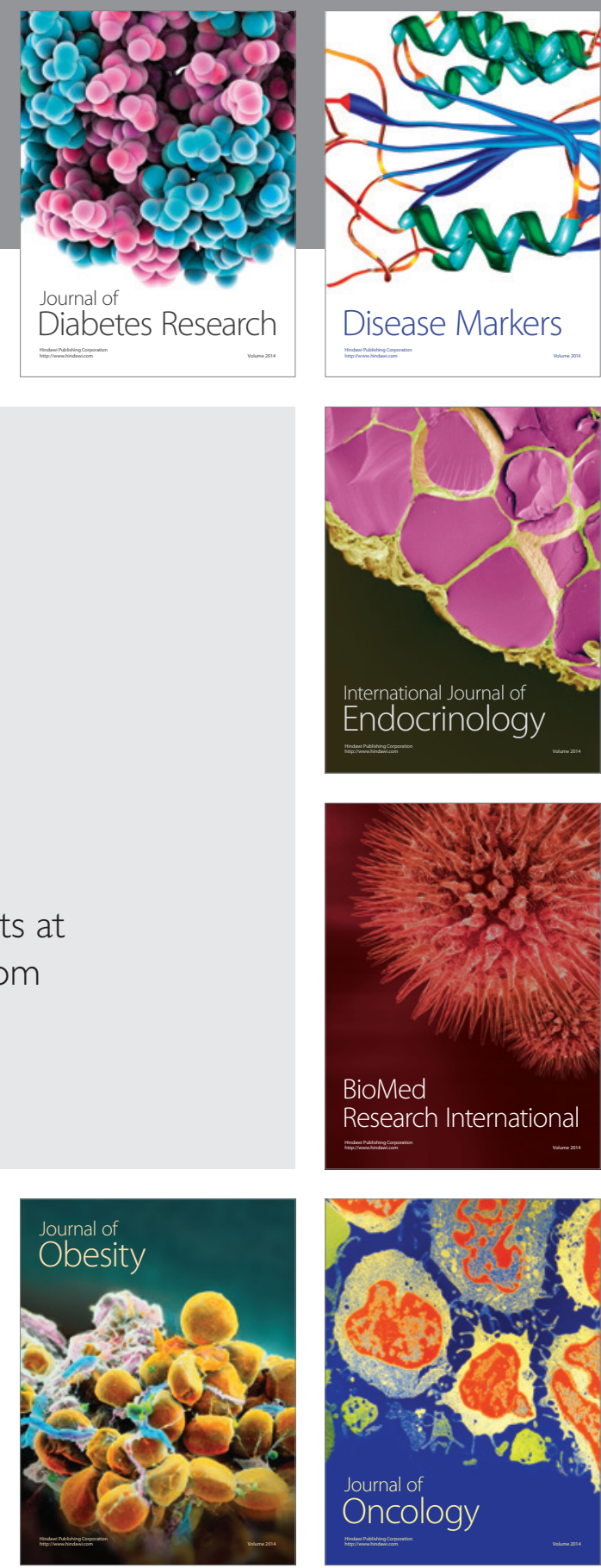

Disease Markers
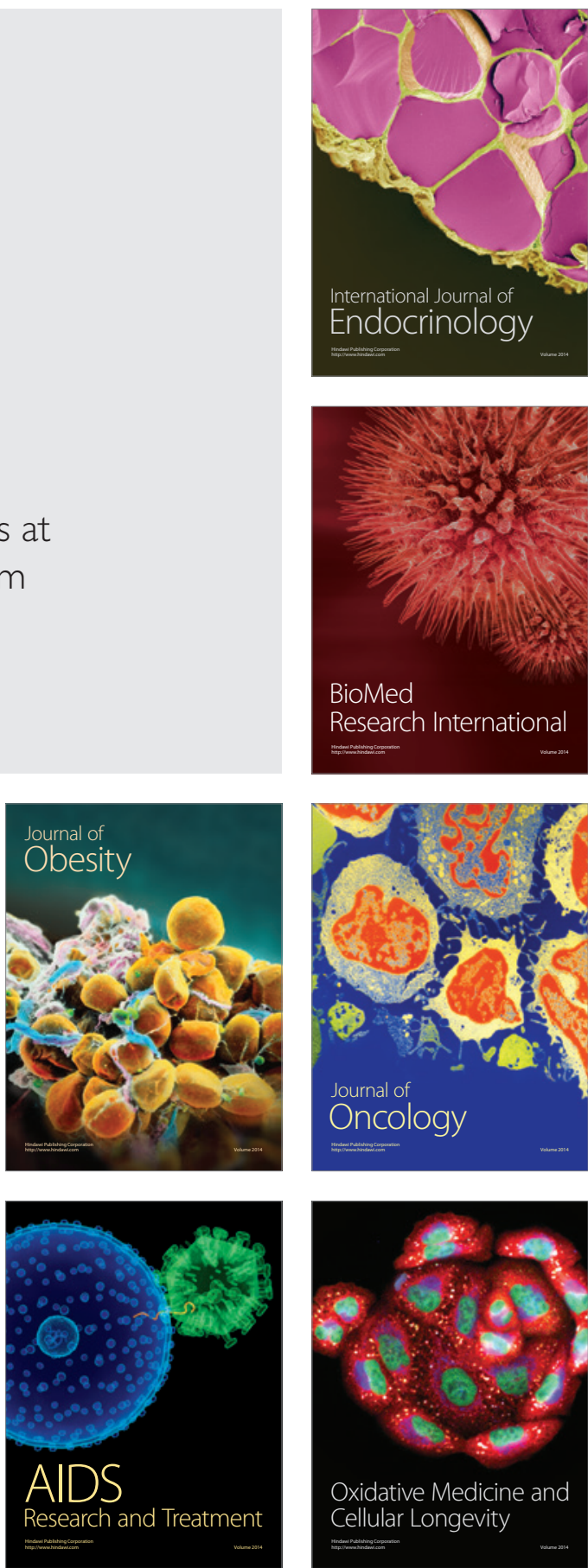